\title{
Tempo de cuidado com o bebê, divisão de tarefas e rede de apoio materna
}

\section{Baby care time, division of tasks and maternal support network}

\author{
Érica Vidal Cunha (orcid.org/0000-0003-0469-4540)' \\ Lígia Ebner Melchiori (orcid.org/0000-0002-4771-8832)2 \\ Manoel Henrique Salgado (orcid.org/0003.0003-2571.6366) ${ }^{3}$
}

\begin{abstract}
Resumo
Considerando a importância da interação mãe-bebê para o desenvolvimento da criança, pesquisadores têm questionado se a inserção da mulher no mercado de trabalho altera a dinâmica dessa interação. Este estudo teve o objetivo de comparar o tempo de cuidado com o bebê, a divisão de tarefas domésticas e a rede de apoio social de mães que não trabalham e mães que trabalham fora de casa. Em relação aos cuidados com o bebê, os resultados apontaram que mães que trabalham fora dedicam mais tempo aos filhos nos finais de semana, enquanto mães que não trabalham dedicam mais tempo durante os dias da semana. Além disso, a mãe foi apontada como maior responsável pelo cuidado com o bebê, seguida pelo pai e a avó. Na divisão de tarefas domésticas, observou-se maior tempo de dedicação pelas mães que não trabalham. De modo geral, a avó apareceu como figura fundamental na rede de apoio materna.
\end{abstract}

Palavras-chave: Emprego. Tarefas domésticas. Rede de apoio social.

\begin{abstract}
Considering the importance of mother-infant interaction for the child's development, researchers have questioned whether the insertion of women in the labor market changes the dynamics of this interaction. This study aimed to compare the time taken to care for the baby, the division of domestic tasks and the social support network of mothers who do not work and the mothers who work outside the home. Regarding baby care, the results indicated that mothers who work outside dedicate more time to their children on weekends, while mothers who do not work dedicate more time during weekdays. In addition, the mother was appointed as the main responsible for the care of the baby, followed by the father and the grandmother. In the division of domestic tasks, more time was devoted by
\end{abstract}

\footnotetext{
1 Universidade Estadual Julio de Mesquita Filho, Bauru, Brasil. E-mail: ericav_cunha@yahoo.com.br.

2 Universidade Estadual Julio de Mesquita Filho, Bauru, Brasil. E-mail: ligia.melch@gmail.com..

${ }^{3}$ Universidade Estadual Julio de Mesquita Filho, Bauru, Brasil. E-mail: henri@feb.unesp.br.
} 
mothers who do not work. In general, the grandmother appeared as a fundamental figure in the maternal support network.

Keywords: Employment. Housework. Social support network.

Quando um bebê nasce, surge a necessidade de a mãe se dividir entre os cuidados com o recém-nascido e com a vida familiar (Jorge, 2011). Contudo, quando a mãe em questão está inserida no mercado de trabalho, findos os meses da licença maternidade, ela terá que se dividir entre os cuidados com o bebê, a família e o trabalho. A literatura aponta como a fase mais difícil, na conciliação de papéis, a que vai do nascimento até o primeiro ano de vida do bebê (Troiano, 2007).

Dados do censo demográfico realizado no ano de 2010 apontam que $76 \%$ das mulheres, na faixa etária de 30 a 34 anos, tinham ao menos um filho (Brasil, 2014). Segundo os dados da Pesquisa Nacional de Amostra de Domicílios - PNAD, em 201 5, 43,7\% da força de trabalho no Brasil era feminina (Brasil, 2016). Além disso, em pesquisa recente, verificouse que, dentre os trabalhadores em tempo parcial (até $30 \mathrm{~h} /$ semana), 28,2\% eram mulheres, contra 14,1\% de homens (Brasil, 2018). A esse respeito, Amaral (2012) e Lopes, DellazzanaZanon e Boeckel (2014) verificaram que a multiplicidade de papéis assumidos pelas mulheres, ao longo das últimas décadas, foi responsável pelas mudanças nos projetos de vida e nas escolhas relacionadas à carreira e aos estudos, fatores que contribuíram para o adiamento da maternidade.

O aumento da escolaridade da mulher se configura como fator que contribui tanto para maior inserção no mercado de trabalho quanto para maior qualidade na maternidade. De acordo com o censo, em 2011, o contingente de mulheres de 20 a 24 anos no ensino superior era $25 \%$ maior que o dos homens da mesma faixa etária, sendo que a média de tempo de estudo da mulher era de 8 anos completos contra 7,6 dos homens (Brasil, 2014). Contudo, verifica-se que as áreas gerais de formação em que as mulheres de 25 anos ou mais estão inseridas, em maior proporção, são Educação, Humanidades e Artes, responsáveis pelos menores registros médios mensais de rendimento e, menores ainda, quando a ocupação é feminina. Esses dados demonstram que, embora a participação 
feminina no mercado de trabalho tenha aumentado, a remuneração e o reconhecimento do mercado não se equipararam aos dos homens.

Entretanto, mesmo que os rendimentos da mulher ainda sejam menores, a inserção qualificada da mulher no mercado de trabalho vem possibilitando o acesso a uma posição mais gratificante, tanto no sentido financeiro, quanto no sentido da realização pessoal e profissional (Guedes \& Alves, 2004). A literatura destaca que esses diferenciais, em muitos casos, fazem com que a mulher opte por trabalhar fora, mesmo que isso implique na sua ausência do campo doméstico e da família. Segundo Crowley (2014), além do reconhecimento pessoal e profissional, o trabalho modela comportamentos de autossuficiência nos filhos e contribui para aumentar o padrão familiar.

Se por um lado o aumento na escolaridade feminina contribui para a inserção qualificada no mercado de trabalho, por outro, pesquisadores apontam que as mulheres com nível superior encontram dificuldades para conciliar as demandas familiares com o trabalho, o que favorece o afastamento do mercado, mesmo que por tempo limitado, para que seja possível a elas dedicarem-se à maternidade (Dias Junior \& Verona, 2016). Para os autores, a ansiedade, culpa e outros sentimentos negativos favorecem a busca por atividades informais com jornadas de trabalho mais flexíveis. Esse achado é corroborado pela pesquisa de Peruchi, Donelli e Marin (2016), que além de constatarem o aumento da ansiedade nas mulheres mães de filhos pequenos, verificaram também o aumento na crença de que elas são as únicas pessoas capazes de cuidar bem das crianças. Associação entre retorno ao trabalho e presença de depressão entre mães que afirmavam não querer retornar ao trabalho $(p=0,001)$ após o nascimento da criança foi verificada nos estudos de Manente e Rodrigues (2016), com 30 primigestas ${ }^{4}$ com bebês entre dois e seis meses. Essa dificuldade pode ser visualizada em pesquisa do IBGE (Brasil, 2013), a qual apontou que apenas 10\% das mulheres que tinham ao menos um filho estudavam. Dentre as mulheres com 25 a 29 anos com um ou mais filhos, 74,1 \% não trabalhavam nem estudavam quando a pesquisa foi realizada. Dessas, 31,5\% possuíam o ensino fundamental incompleto, $20 \%$ o ensino fundamental completo ou o médio incompleto, $39,2 \%$ o ensino médio completo e apenas 9,3\% possuíam ensino superior completo.

\footnotetext{
4 Que gesta pela primeira vez; primigrávida. Mulher em sua primeira gestação.
} 
Nesse contexto, a creche tem sido apontada como um dos mecanismos que pode favorecer o retorno das mães ao trabalho, sendo utilizada como ferramenta de apoio para várias famílias. A mesma pesquisa do IBGE, citada anteriormente, apontou que, das mulheres com filhos entre zero e três anos de idade que frequentam creche, 71,7\% estavam empregadas na semana de referência da pesquisa. Entretanto, quando nenhum filho frequentava creche, apenas 43,9\% trabalhavam fora de casa (Brasil, 2013).

Segundo dados obtidos por Milkie, Nomaguchi e Denny (2015), observa-se a crença de que as mães são mais sensíveis às necessidades das crianças do que outros adultos e, por isso, o tempo que elas passariam com os filhos seria único e insubstituível. Ademais, ao sair para o trabalho, a mãe estaria, de certa forma, privando a criança de seu convívio e dos benefícios advindos dele (Wall, 2013). Contudo, Craig, Powell e Smyth (2014) ressaltaram que é importante identificar se, no tempo que as mães passam com os filhos, elas estão realmente engajadas na interação, conversando e brincando, ou somente supervisionando suas ações.

Alguns estudiosos (Bossardi, 2011; Craig, Powell, \& Smyth, 2014; Faria, Santos, \& Fuertes, 2014; Giallo, Treyvaud, Cooklin, \& Wade, 2013; Huston \& Aronson, 2005; Mendonça \& Matos, 2015; Milkie, Nomaguchi, \& Denny, 2015), pautados na questão do tempo da mãe com o bebê e na conciliação entre trabalho e maternidade, têm procurado compreender, entre outros pontos, se o tempo que a mãe dedica ao filho sofre influência do trabalho materno. Em um estudo realizado nos Estados Unidos, com 1364 mães que podiam optar por trabalhar ou não, sendo $91 \%$ com médio ou alto nível educacional e $86 \%$ casadas, Huston e Aronson (2005) buscaram analisar se o trabalho materno tem relação com o tempo exclusivo que as mães passam interagindo socialmente com seus bebês e cuidando deles. Os autores concluíram que as mães que trabalhavam fora passavam, por semana, cerca de uma hora a menos com seus bebês do que as mães que não trabalhavam fora. Isso se justifica porque as primeiras reduziam o tempo em tarefas domésticas, organização, lazer e atividades sociais para se dedicarem mais aos filhos, ou seja, mais tempo brincando, conversando ou segurando seus bebês, e menos tempo em cuidados instrumentais. O tempo disponível para os filhos foi um indicador de cuidados maternos positivos e de qualidade no ambiente doméstico. Para Huston e Aronson (2005), o emprego pode contribuir com fatores 
positivos, seja por causa da renda, seja da estimulação social e intelectual que a mãe oferece ao bebê.

O engajamento (interação, cuidado, afeto, provimento e responsabilidade) de mães que trabalhavam fora também foi um dos pontos estudados por Bossardi (2011) e Giallo, Treyvaud, Cooklin e Wade (2013). Ambos estudos apontaram que a jornada de trabalho dos pais tem influência no engajamento com o bebê. Verificou-se que quando a jornada de trabalho materna era menor ou em tempo parcial, o engajamento com os filhos era maior. Bossardi (2011) ainda ressaltou que as mães dedicavam mais tempo aos cuidados básicos com o bebê quando trabalhavam menos. Entre as atividades realizadas, Giallo et al. (2013) apontaram que as mais comuns eram brincadeiras dentro de casa, relatadas por $50 \%$ das participantes, enquanto brincar ao ar livre e contar histórias foram as atividades menos citadas. Ambos os estudos ressaltaram que, mesmo quando a mãe trabalhava em tempo integral, o cuidado e a atenção que dispensava à criança eram predominantes em relação aos cuidados dispensados por outros membros da família.

Faria, Santos e Fuertes (2014) realizaram uma revisão de literatura na qual questionaram qual fator mais influencia a vinculação pais-crianças: o tempo dedicado à interação ou o gênero dos pais. Assim como Bossardi (2011), as autoras descobriram que as mães dedicavam mais tempo aos seus filhos do que os pais. Além disso, apontaram que a qualidade do tempo passado com a criança tinha mais importância do que a quantidade do tempo dedicado. Ademais, Faria et al. (2014) ressaltaram que mães que brincavam e passeavam com seus filhos tendiam a estabelecer uma relação mais segura e interação mais positiva do que mães que não o faziam.

Considerando os estudos com tendência à valorização da maternidade intensiva, Craig et al. (2014) realizaram uma pesquisa na Austrália, comparando dados de anos distintos (1992 e 2006), visando identificar mudanças ao longo do tempo relacionadas aos cuidados e comportamentos parentais em relação aos filhos. Em suma, os autores encontraram que, embora a média geral de horas que os pais dedicaram aos filhos tenha sido menor em 2006, o tempo gasto em lazer e atividades sociais praticamente não se alterou quando comparado a 1992. Com relação ao trabalho materno, os dados demonstraram que estar fora do mercado de trabalho não se traduziu em aumento do 
tempo de lazer ou atividades sociais com os filhos. O mesmo ocorreu com as mães que trabalhavam em meio período: os dados não apontaram aumento no tempo dedicado ao lazer e/ou social quando comparados aos de 1992. Para os autores, esses comportamentos parentais refletiram o esforço que os pais, mesmo com as alterações no mercado de trabalho, têm realizado para priorizar o tempo dedicado aos filhos.

$\mathrm{Na}$ mesma linha dos estudos relacionados à maternidade intensiva, Milkie et al. (2015), nos Estados Unidos, analisaram se o tempo que as mães passavam com seus filhos, de 3 a 18 anos, tinha relação com os resultados comportamentais, emocionais e acadêmicos dos filhos. Os dados não apontaram associações estatisticamente significativas entre tempo materno de qualquer tipo e os resultados da criança. Contudo, a educação materna, a renda familiar e a estrutura familiar se relacionaram a alguns resultados. Por exemplo, quanto maior o período de educação formal materna, maior era o desempenho das crianças em leitura e matemática, e, também, a renda familiar foi positivamente associada ao desempenho em matemática das crianças. Contudo, para os adolescentes, menor tempo disponível ao filho por parte da mãe foi associado negativamente aos comportamentos de risco, e o menor tempo dedicado por mãe e pai foi associado ao maior uso de substâncias ilícitas. Os dados demonstram que o tempo que os pais passam com os filhos tem mais impacto na adolescência do que na infância. Os autores ressaltam que o foco, nesse estudo, foi o tempo de engajamento materno, e não a qualidade do tempo dispensado aos filhos.

O tempo passado em família tem sido ressaltado como ponto de apoio, tanto para os filhos, quanto para os pais. Segundo Craig et al. (2014), os pais têm optado por realizar o lazer em família, abdicando-se do lazer pessoal, para priorizar mais tempo com os filhos. Para os autores, o lazer compartilhado facilita o vínculo entre os membros e proporciona momentos agradáveis e divertidos para pais e filhos. Também nessa direção, metade das participantes da pesquisa realizada por Mendonça e Matos (2015) apontaram que a satisfação encontrada junto à família, principalmente na interação com os filhos, é um fator que contribui para atenuar o estresse decorrente do trabalho materno. Entretanto, nesse mesmo estudo, mais da metade dos pais relataram cansaço físico e psicológico ocasionado pelo trabalho que, por sua vez, competiu com a disponibilidade para a interação positiva com o filho. Para Faria et al. (2014), mães com trabalhos estressantes ou inseridas em 
jornadas de trabalho irregulares apresentam maior dificuldade de se envolverem em relações positivas com seus filhos.

Em estudo sobre experiência da maternidade relacionada ao trabalho, a maternidade aliada à dedicação ao ambiente doméstico foi considerada desafiadora e cansativa para todas as mulheres, independente de trabalharem ou não fora de casa (Quadrelli, 2016). Esse cenário ocorreu mesmo entre aquelas que contavam com o auxílio das avós e/ou creches nos afazeres e cuidados com o bebê.

Segundo a PNAD (Brasil, 2018) de 2016 a 2017, embora a realização de afazeres domésticos e o cuidado de pessoas tenha crescido entre os homens nos últimos anos, as mulheres dedicam uma média de 20,9 horas semanais nessas atividades, contra 10,8 horas dedicadas por eles. A pesquisa também apontou que $76,4 \%$ dos homens realizam trabalho doméstico. Dentre as mulheres, esse número chega a $97 \%$. Observou-se que, quanto maior o nível de instrução dos homens, mais realizam atividades domésticas: $73 \%$ dentre os que possuem menor escolaridade, e $83,8 \%$ dentre os que possuem nível superior completo.

Para Dush, Yavorsky e Schoppe-Sullivan (2018), mesmo entre casais de classes mais altas, há práticas desiguais de trabalho. Esses autores, em suas pesquisas, constataram que homens estavam envolvidos em atividades de lazer ao mesmo tempo em que suas esposas realizavam trabalhos domésticos ou estavam com o bebê. Contudo, não foi verificada alteração no tempo de lazer das mães enquanto seu companheiro estava no trabalho.

A fim de explorar, entre outras questões, a visão masculina com relação à divisão de tarefas, Teykal e Rocha-Coutinho (2007) realizaram uma pesquisa com cinco homens que trabalhavam e tinham relacionamento conjugal estável. Os resultados apontaram para uma mudança discreta no padrão tradicional, demonstrando maior participação masculina no espaço doméstico. Contudo, a participação do homem era vista como colaboração e não como responsabilidade. Resultado similar foi obtido no estudo de Jablonski (2010), que contou com 20 casais de classe média. Porém, nessa pesquisa, os homens relataram contribuição maior do que a apontada por suas esposas. $\mathrm{O}$ autor declara que, considerando que as entrevistadoras eram mulheres, as respostas podem ter sido dadas de acordo com o que se considera politicamente correto, ou ainda, que os homens superestimavam as atividades que realmente faziam no ambiente doméstico. 
Borsa e Nunes (2011) e Oliveira e Traesel (2008) discutiram que a baixa adesão masculina à divisão de tarefas pode decorrer da resistência das próprias mulheres em abrir mão do monopólio das funções ditas do lar, pois que essas funções ainda são valorizadas entre elas. Para os autores, esse é um campo historicamente relacionado ao poder feminino, havendo uma ambivalência de sentimentos em que, ao mesmo tempo que reivindicam maior participação do companheiro, também demonstram resistência no compartilhamento de papéis com os homens, desvalorizando o trabalho doméstico que eles eventualmente realizam.

Para contribuir com a mulher no desafio da divisão de papéis e tarefas, a ajuda profissional e o apoio de familiares no cuidado com os filhos foram apontados como fatores que contribuíram para aumentar a disponibilidade da mulher para os filhos, a família e o trabalho (Jablonski, 2010; Teykal \& Rocha-Coutinho, 2007). Além disso, verificou-se que o suporte à mãe por parte do companheiro e familiares esteve associado à redução de sintomatologias depressivas, proporcionando efeitos positivos à díade durante e após o nascimento do bebê, contribuindo para o bem-estar físico e emocional materno (Souza, Souza, \& Rodrigues, 2013; Theme Filha, Ayers, Gama, \& Leal, 2016).

Em uma pesquisa com 30 mães primíparas, com bebês entre dois e seis meses de vida, $77 \%$ das participantes relataram colaboração do parceiro com os cuidados referentes ao bebê. Contudo, os outros tipos de apoio recebidos advinham dos avós e outros familiares (Manente \& Rodrigues, 2016). Nesse contexto, pesquisando sobre trabalho e cotidiano das mulheres, Ávila e Ferreira (2014) verificaram que 74\% das participantes do estudo contavam com algum tipo de ajuda para cuidar da casa. Entretanto, entre as mulheres casadas, $71 \%$ afirmavam que a ajuda não provinha do marido. Entre as mães solteiras ou viúvas, a principal fonte de auxílio era a avó materna.

Sentimentos de tranquilidade e segurança foram relatados por profissionais da saúde que se tornaram mães e puderam contar com o apoio de familiares. Além disso, o apoio da família extensa, tios, tias e amigos, torna-se mais forte quando há proximidade geográfica e afetiva (Rodrigues, Mazza, \& Harumi, 2014). Observa-se que o suporte às mães atua como fator de proteção à maternidade, e faz-se importante uma rede que ofereça auxílio tanto 
com relação ao bebê, quanto aos cuidados domésticos e assistência à mulher (Manente \& Rodrigues, 2016).

Considerando a importância dessas questões para a mãe e seu bebê, o objetivo geral desta pesquisa foi identificar diferenças no tempo de cuidado materno com o bebê em função de seu trabalho externo, bem como conhecer a divisão de tarefas entre o casal e a rede de apoio percebida pelas mães. Os objetivos específicos foram: a) caracterizar e comparar as díades participantes em termos de atividades, divisão de tarefas e rede de apoio familiar; b) descrever e comparar o tempo de cuidado que as mães que trabalham fora, remuneradas ou não, dedicam exclusivamente aos bebês.

\section{Método}

\section{Aspectos éticos}

Este estudo faz parte de uma pesquisa mais ampla e foi submetido à Plataforma Brasil, conforme as condições estabelecidas na resolução 466/2012 da Comissão Nacional de Ética em Pesquisa, CAAE 61211616.9 .0000 .5398 , obtendo o parecer favorável de número 1.817 .775 .

Às participantes foram entregues duas cópias do Termo de Consentimento Livre e Esclarecido - TCLE, que foram assinadas por elas e pela pesquisadora, cabendo a cada pessoa uma via do termo para guarda. Nessa ocasião, as participantes foram informadas sobre o objetivo do projeto, as atividades pertinentes a ele, o sigilo das informações pessoais fornecidas e sobre a possibilidade de desistência, que poderia ocorrer, sem ônus, em qualquer fase deste trabalho.

\section{Participantes}

Participaram deste estudo 16 díades mães-bebês, selecionadas por conveniência, todas residindo em área urbana, sendo que oito mães exerciam atividade remunerada fora de casa e oito não. Todas eram mães biológicas, com idade entre 27 a 36 anos. Todas as mães que trabalhavam possuíam nível superior completo. Dentre as que não trabalhavam, 
duas possuíam pós-graduação. Somente uma mãe possuía nível técnico. Todas as participantes moravam com o esposo ou companheiro adulto e possuíam entre dois e nove anos de relacionamento $(m=5,5$ anos). A renda familiar de duas mães que não trabalhavam era de cinco salários mínimos; todas as demais participantes tinham renda familiar maior ou igual a sete salários mínimos. Dentre as mães que trabalhavam fora, três eram profissionais liberais, três trabalhavam no setor administrativo e duas no setor da saúde/educação. Para cinco mães, a jornada diária de trabalho externo era de seis horas, e para três, era maior, chegando a 8 horas diárias. Os companheiros estavam empregados como profissionais liberais, no setor administrativo/público, saúde, educação e na iniciativa privada, todos com jornada igual ou maior que oito horas diárias. Todas as participantes estavam na primeira união; os parceiros tinham entre 30 e 37 anos e nas residências moravam apenas pai, mãe e filhos. Os bebês possuíam entre 12 e 19 meses de idade, sem risco de desenvolvimento relatado, sendo 12 meninos e quatro meninas. Dentre os bebês que frequentavam creche, três eram filhos de mães que trabalhavam e cinco, filhos de mães que não trabalhavam fora de casa. Os outros bebês estavam sob cuidados de familiares ou empregada durante o trabalho materno.

\section{Local}

Os dados foram coletados em uma sala de atendimento do Centro de Psicologia Aplicada (CPA) de uma universidade paulista, do interior do estado. Apenas no caso de duas díades, por indisponibilidade das mães para se deslocarem ao CPA, os dados foram coletados nas residências.

\section{Instrumentos}

Para caracterizar as famílias, foi utilizado o Questionário de Caracterização do Sistema Familiar Versão - Pais ou Responsável de Dessen (2009), com ênfase nos dados sociodemográficos, divisão de tarefas domésticas, cuidados diários com o bebê e rede de apoio social. 
O tempo de cuidado/interação social das mães com os bebês foi analisado a partir do Protocolo de Atividade Diária, construído para esta pesquisa com base no instrumento "Atividades cotidianas da sua criança" de Kobarg (2006). Investigou-se o tempo de dedicação exclusivo da mãe com o bebê durante um dia da semana e no final de semana, a quantidade de horas gastas em diferentes atividades rotineiras, como cozinhar, arrumar a casa, bordar, ler etc., e atividades de lazer com e sem a criança. Além disso, investigou-se com quem a mãe poderia contar para ajudá-la a cuidar do bebê durante a semana e nos finais de semana.

\section{Procedimento de coleta de dados}

As mães foram contatadas e foram agendados dia e horário para esclarecimentos sobre a realização da pesquisa. Após esclarecidas todas as dúvidas, as participantes assinaram o TCLE, aceitando participar da investigação. Em seguida, foram entregues os instrumentos, que ficaram disponíveis para resposta por aproximadamente uma semana. Algumas mães optaram pela devolução via e-mail; outras o fizeram pessoalmente, conforme sua preferência.

\section{Procedimento de análise dos dados}

Os dados obtidos por meio do Questionário de Caracterização do Sistema Familiar Versão - Pais ou Responsável foram categorizados de acordo com as respostas obtidas e objetivos do estudo, seguindo a orientação da autora (Dessen, 2009).

Os dados do Protocolo de Atividade Diária foram computados de forma a se obter mensuração do tempo de interação exclusiva entre mãe-bebê e categorização das atividades que ocorreram na interação da díade, ou seja, quanto tempo a mãe dedicava exclusivamente ao bebê e em quais atividades dedicava maior ou menor tempo. As respostas obtidas foram agrupadas em três categorias: Cuidados instrumentais (trocar fralda, banho, colocar para dormir); Alimentação (amamentação, mamadeira, almoço, jantar e lanches) e Lazer do bebê (brincadeiras em geral, música, histórias etc.). Também foram tabelados e comparados os 
dados referentes às atividades que a mãe realizava durantes a semana, tais como: trabalhos domésticos; outras atividades (costurar, bordar, estudar, ler, escrever); atividades de lazer sem a criança e atividades de lazer com a criança. Para as comparações entre os grupos, foram utilizadas estatísticas descritivas (médias) e o teste não paramétrico Mann-Whitney (amostra não emparelhada). As análises estatísticas foram realizadas por meio do software Statistical Package for the Social Sciences (SPSS). Contudo, considerando o tamanho reduzido da amostra, foram discutidos os dados que apresentaram significância $p<0,09$.

\section{Resultados}

Os dados obtidos visaram identificar se havia diferença significativa entre os grupos de mães - que trabalhavam fora ou não - em relação ao tempo dedicado exclusivamente a cuidados e interação com o bebê, divisão de tarefas domésticas e rede de apoio social.

As participantes foram questionadas sobre a quantidade de horas que passavam em interação exclusiva com o bebê, em um dia comum do meio de semana e do fim de semana. Os resultados da comparação entre os grupos podem ser verificados na Tabela 1 a seguir: 


\section{Tabela 1}

Comparação do tempo de atividade exclusiva da mãe (em minutos), com a criança, em um dia da semana e um dia do fim de semana

\begin{tabular}{|c|c|c|c|c|c|}
\hline & & $\begin{array}{c}\text { Exerce atividade } \\
\text { remunerada }\end{array}$ & $\begin{array}{c}\text { Não exerce atividade } \\
\text { remunerada }\end{array}$ & & \\
\hline Categ & as de atividade & Média & Média & $U$ & $P$ \\
\hline$\underset{\frac{\pi}{\tau}}{\stackrel{\tau}{\tau}}$ & Cuidados instrumentais & 65,6 & 59,4 & 69 & 0,9581 \\
\hline$\frac{\pi}{0}$ & Alimentação & 84,4 & 80,6 & 72 & 0,7132 \\
\hline $\bar{\Delta}$ & Lazer do bebê & 104,4 & 151,9 & 55,5 & 0,2076 \\
\hline 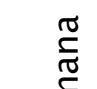 & Cuidados instrumentais & 71,9 & 33,1 & 85 & 0,0831 \\
\hline$\frac{0}{0}$ & Alimentação & 96,3 & 68,1 & 78,5 & 0,2936 \\
\hline$i=$ & Lazer do bebê & 159,4 & 112,5 & 78 & 0,3184 \\
\hline
\end{tabular}

Teste Mann-Whitney * $\mathrm{p}<0,09$.

Fonte: Elaborada pelos autores.

É possível observar que as mães que trabalhavam fora dedicavam mais tempo em cuidados instrumentais com o bebê, cuidados com a alimentação e em atividades de lazer com os filhos (principalmente nos finais de semana) do que as mães que não trabalhavam fora. Especialmente no que diz respeito aos cuidados instrumentais, os dados demonstram diferença significativa, ou seja, nos finais de semana, mães que trabalhavam fora dedicavam mais tempo à troca de fralda, banho, e fazendo o bebê dormir.

Na Tabela 2 podem ser visualizados os dados referentes à divisão de responsabilidades no cuidado com o bebê. Observa-se que em ambos os grupos houve maior número de respostas compatíveis com a divisão de tarefas entre pai e mãe, contudo, os dados demonstraram que algumas mães realizavam as tarefas sozinhas. Nota-se também que, nas famílias em que a mãe trabalhava fora, havia outras pessoas no suporte, além do parceiro, tal como a avó e outros familiares. A avó ainda foi citada por ambos os grupos como sendo a pessoa com quem se pode contar para auxiliar nos cuidados do bebê. 
Destaca-se que a categoria "levar para atividade de lazer" foi apontada cinco vezes, em ambos os grupos de mães, como sendo uma atividade compartilhada pelo casal.

Tabela 2

Responsabilidades com o bebê

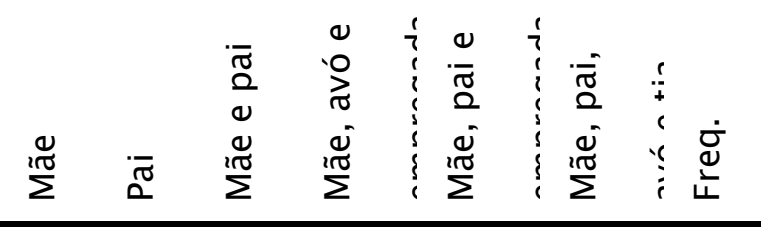

Mães que exercem atividade remunerada

\begin{tabular}{|c|c|c|c|c|c|c|c|}
\hline Alimentação e banho & 2 & & 2 & 1 & & 3 & 8 \\
\hline Levar à escola & 1 & & 2 & & & & 3 \\
\hline Ler/contar histórias & 2 & & 3 & & 1 & 1 & 7 \\
\hline Levar para atividade de lazer & 1 & & 5 & & 1 & 1 & 8 \\
\hline Colocar para dormir & 3 & & 2 & 1 & & 2 & 8 \\
\hline Brincar & 1 & & 2 & & 1 & 4 & 8 \\
\hline$F$ & 10 & 0 & 16 & 1 & 3 & 11 & \\
\hline \multicolumn{8}{|c|}{ Mães que não exercem atividade remunerada } \\
\hline Alimentação e banho & 4 & & 3 & & & 1 & 8 \\
\hline Levar à escola & 3 & 2 & & & & & 5 \\
\hline Ler/contar histórias & 1 & & 3 & 2 & & & 6 \\
\hline Levar para atividade de lazer & 1 & & 5 & & & 2 & 8 \\
\hline Colocar para dormir & 4 & & 4 & & & & 8 \\
\hline Brincar & & & 3 & & & 5 & 8 \\
\hline$F$ & 13 & 2 & 18 & 2 & & 8 & \\
\hline
\end{tabular}

Fonte: Elaborada pelos autores.

No grupo de mães que não exercem atividade remunerada, dentre cinco crianças que frequentavam a creche em período parcial, dois pais foram citados como responsáveis por 
levarem o bebê até a instituição, embora a mãe ainda tenha recebido maior número de respostas para essa questão.

$\mathrm{Na}$ Tabela 3, encontram-se os dados relacionados ao tempo (em minutos) que as mães dos dois grupos dedicavam às outras atividades que não envolviam o cuidado exclusivo com o bebê.

Tabela 3

Comparação do tempo em minutos de atividades que as mães realizam durante a semana

\begin{tabular}{lccccc}
\hline & $\begin{array}{c}\text { Exerce atividade } \\
\text { remunerada }\end{array}$ & $\begin{array}{c}\text { Não exerce atividade } \\
\text { remunerada }\end{array}$ & & \\
\cline { 2 - 5 } Atividades & Média & Média & $U$ & $p$ \\
\hline Trabalhos domésticos & 356,3 & 896 & 42 & $0,0074^{*}$ \\
Outras atividades no lar & 469 & 401 & 71,5 & 0,7527 \\
Ativ. lazer sem o bebê & 30 & 112,5 & 58,5 & 0,3446 \\
Ativ. lazer com o bebê & 405,5 & 300 & 81,5 & 0,1722 \\
\hline
\end{tabular}

Teste Mann-Whitney * $\mathrm{p}<0,09$.

Fonte: Elaborada pelos autores.

Verificou-se diferença significativa apenas nos "trabalhos domésticos", nos quais o grupo de mães que não trabalhava fora dedicou significativamente mais tempo.

Embora os dados não tenham apontado outras diferenças estatisticamente significativas, o grupo de mães que trabalhava fora praticamente não realizava atividades semanais de lazer sem a companhia da criança. Por outro lado, no outro grupo de mães o lazer sem a criança, mesmo que em número reduzido de horas, era mais frequente. Ademais, observou-se que a mãe que trabalhava fora também dedicava mais tempo em atividades semanais de lazer com a criança (como almoçar fora, passeios, visitas e shopping).

Os dados da Tabela 4 demonstram que os afazeres domésticos continuavam em grande parte sob responsabilidade da mulher. Contudo, no grupo de mães que exercia 
atividade remunerada, a participação do pai nos afazeres domésticos foi um pouco maior, sendo que dois deles assumiam com exclusividade as atividades de lavar/passar ou comprar alimentos. Com relação à compra de alimentos, observou-se considerável participação do pai em ambos os grupos, apesar da atividade ser realizada junto com a esposa. Destaca-se que no grupo de mães que não exercia atividade remunerada, cozinhar demonstrou ser responsabilidade preponderante da mulher.

\section{Tabela 4}

\section{Responsabilidades com os afazeres domésticos}

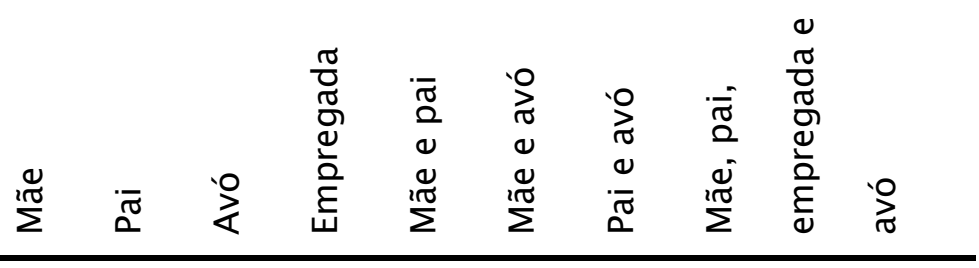

Mães que exercem atividade remunerada

\begin{tabular}{|c|c|c|c|c|c|c|c|c|}
\hline Limpar a casa & 3 & & 1 & & 2 & & & 2 \\
\hline Cozinhar & 3 & & 1 & & 1 & 1 & 1 & 1 \\
\hline Lavar/passar & 3 & 1 & & & 1 & 1 & & 2 \\
\hline Comprar alimentos & 1 & 1 & & & 5 & & & 1 \\
\hline Orientar empregada & 3 & & & & 1 & & & \\
\hline$F$ & 13 & 2 & 2 & 0 & 10 & 2 & 1 & 6 \\
\hline \multicolumn{9}{|c|}{ Mães que não exercem atividade remunerada } \\
\hline Limpar a casa & 3 & & 1 & 3 & & 1 & & \\
\hline Cozinhar & 5 & & 1 & & 1 & 1 & & \\
\hline Lavar/passar & 2 & & 1 & 3 & & 1 & & 1 \\
\hline Comprar alimentos & 3 & & & & 5 & & & \\
\hline Orientar empregada & 4 & & & & 1 & & & \\
\hline$f$ & 18 & 0 & 3 & 6 & 7 & 3 & 0 & 1 \\
\hline
\end{tabular}

Fonte: Elaborada pelos autores. 
Outro aspecto interessante foi que, no grupo de mães que não trabalhava fora, a ajuda da empregada doméstica foi citada mais vezes. Além disso, observou-se que no grupo de mães que exercia atividade remunerada, o suporte partia de diversos membros da família: pai, avós, tios do bebê e empregadas. Por outro lado, no grupo de mães que não exercia atividade remunerada, a maior parte das respostas concentrou-se nas quatro primeiras colunas da tabela, que correspondem à responsabilidade de apenas uma pessoa, seja ela mãe, avó ou empregada. Outro ponto a ser destacado é a ausência total da figura paterna nas atividades domésticas nesse grupo.

A Tabela 5 apresenta dados sobre a rede de apoio percebida pelas mães para além dos cuidados com o bebê e dos afazeres domésticos, bem como a sua importância na rotina da família.

\section{Tabela 5}

Rede de apoio familiar

\begin{tabular}{llll}
\hline Rede de apoio & $\begin{array}{l}\text { Mães que } \\
\text { trabalham fora }\end{array}$ & $\begin{array}{l}\text { Mães que não } \\
\text { trabalham fora }\end{array}$ & \multicolumn{1}{l}{ Importância } \\
\hline Não familiar & & & \\
\hline Amigos & 4 & 2 & Interação com outras crianças \\
Vizinhos & 2 & 1 & Importante \\
Func. & 0 & 2 & \\
Doméstica & & & Desenvolvimento/cuidado do bebê \\
\hline Instituição/ & & 4 & Acompanhamento de rotina \\
profissional & & 2 & \\
\hline Berçário & 2 & &
\end{tabular}

Fonte: Elaborada pelos autores.

Os dados apontam para maior presença dos amigos na rede de apoio não familiar entre as mães que trabalhavam fora. Enquanto no outro grupo de mães, os profissionais da 
rede de apoio institucional foram citados mais vezes, sendo o berçário a forma de apoio institucional utilizada por metade delas.

\section{Discussão}

Participaram deste estudo mães que exerciam trabalho remunerado fora de casa e mães que não trabalhavam fora. Considerando o tempo de dedicação da mãe ao bebê, verificou-se que, nos finais de semana, o tempo de dedicação entre as mães que trabalhavam foi maior, em todas as categorias, quando comparadas às mães que estavam em casa. Observou-se que as mães que trabalhavam fora tentavam compensar sua ausência se dedicando mais à criança quando em casa durante a semana e nos finais de semana, enquanto que a mãe que não trabalhava reduzia seu tempo de atividades com o bebê nos finais de semana. Essa redução pode indicar a divisão dos cuidados com o pai, que aos finais de semana possui mais tempo disponível. Assim sendo, é possível supor que o pai também "compensaria" sua ausência semanal nesses momentos.

Esses achados vão na direção dos estudos de Craig et al. (2014), e Huston e Aronson (2005), que apontam para a equivalência de horas gastas, nos cuidados com os filhos, entre mães que trabalham fora de casa e mães que não trabalhavam fora. Para os autores, as mães que estão inseridas no mercado de trabalho reduzem o tempo em tarefas de organização do lar e cuidados pessoais tanto durante a semana quanto aos finais de semana, dedicando-se mais aos bebês, seja dando banho, alimentando, trocando fraldas ou brincando e conversando. Os autores apontam que a maior disponibilização de tempo para a criança pode indicar cuidados maternos mais positivos e maior qualidade no ambiente doméstico.

Além disso, observou-se que as mães que não trabalhavam fora realizavam mais atividades de lazer sem a criança do que as mães que trabalham fora, para quem o lazer pessoal, sem o bebê, foi quase zero. Ou seja, elas não têm tempo disponível para lazeres individuais ou com o parceiro, como o cinema, por exemplo, citado por elas como uma das atividades que não realizaram após o nascimento do filho, dados que corroboram os achados de Craig et al. (2014) e Huston e Aronson (2005). 
Além do tempo materno, os dados ainda demonstram participação dos pais e das avós no cuidado com o bebê. Contudo, a mãe ainda foi identificada, em algumas famílias, como única responsável pelas tarefas. Tal fato ficou mais evidente entre as mães que não trabalhavam fora, das quais metade das participantes apontou serem as únicas responsáveis por alimentar e colocar o bebê para dormir. Esses achados corroboram os estudos de Bossardi (2011) e Faria et al. (2014), que apontaram que os cuidados dispensados pelas mães ainda são maiores, em quantidade, que os cuidados dispensados por outros membros da família. Contudo, observou-se um fato interessante: a avó foi bastante citada na fala de todas as participantes, principalmente entre as mães que trabalhavam, demonstrando que, mesmo quando os filhos estão adultos, a mãe (hoje, avó) continua no suporte ao filho e, por conseguinte, ao neto, ou seja, à família extensa como um todo. Os dados sugerem, portanto, que o papel de cuidado materno parece ultrapassar a construção familiar de uma geração, perpetuando o papel de cuidadora, a despeito da idade dos filhos.

Dessen e Braz (2000) também constataram a divisão de tarefas entre mãe, pai e avó, sendo a última apontada como atuante na rotina da casa, educação e criação dos filhos por meio da transmissão de valores e regras. Além dos pais e avós, Bossardi (2011) apontou a presença de outros membros da família no cuidado com os filhos, tais como: tios, funcionárias domésticas, entre outros, corroborando os achados desta pesquisa. A literatura Jablonski, 2010; Souza et al., 2013; Teykal \& Rocha-Coutinho, 2007; Theme Filha et al., 2016) tem ressaltado a importância da participação dos familiares e ajuda de profissionais para garantir maior eficácia materna na divisão de tarefas, no cuidado com os filhos e com a família e no trabalho. Além disso, o suporte às mães tem sido associado ao aumento do bem-estar emocional materno e redução de sintomas depressivos, fatores importantíssimos para a relação mãe-bebê. Silva (2010) aponta que o trabalho da mãe fora de casa se configura como principal motivo da inclusão da avó no contexto familiar, e sua participação na família contribui também para seu próprio bem-estar e realização, na medida em que se sente útil e transmite valores familiares.

Contudo, embora esta pesquisa tenha verificado uma rede considerável de apoio em relação aos cuidados com o bebê, esta não se fez verdadeira quanto à divisão de tarefas domésticas, mostrando que ainda tem muito a melhorar. Isso corrobora os achados da 
literatura que apontaram baixa adesão do companheiro ao trabalho doméstico Jablonski, 2010; Manente \& Rodrigues, 2016; Teykal \& Rocha-Coutinho, 2007). O presente estudo apontou que limpar a casa, cozinhar, lavar e passar estavam sob responsabilidade quase exclusiva da mulher, principalmente no grupo de mulheres que não exerciam trabalho remunerado e dedicavam, aproximadamente, 15 horas semanais a essas atividades. A quantidade de horas apontadas na pesquisa, embora significativa na comparação entre os grupos, está abaixo da média nacional (22,3 horas) de dedicação das mulheres aos afazeres domésticos (Brasil, 2013). Contudo, mais da metade das participantes contavam com o auxílio de uma empregada doméstica, o que parece ter contribuído para o resultado abaixo da média nacional.

Conforme apontado por Jablonski (2010) e Teykal e Rocha-Coutinho (2007), muito há que se fazer em relação à participação do homem nos trabalhos domésticos. Contudo, mesmo entre as mulheres, parece ser necessária uma mudança na concepção das responsabilidades do casal dentro de casa. Nota-se nas respostas das participantes que elas consideram o trabalho doméstico como mais de sua responsabilidade que do outro, o que reforça o papel da mulher como "cuidadora do lar".

A literatura aponta que esse papel de ajuda, e não de corresponsabilidade, pode ser reforçado pelas próprias mulheres e pela cultura na qual estão inseridas, visto que que o papel materno e de boa "esposa", a que cuida do lar e da família, é valorizado entre elas (Borsa \& Nunes, 2011; Oliveira \& Traesel, 2008; Santos, 2014). Com relação às mães que deixaram suas profissões para dedicar-se exclusivamente à maternidade, Santos (2014) aponta que elas concebem o papel de cuidadora como inerente à sua condição de mulher, justificando as escolhas que fizeram em nome dos filhos e da casa.

Ademais, embora de maneira discreta, este estudo identificou participação exclusiva do pai no levar à escola, o que pode expressar sua tentativa de maior participação na rotina do filho, visto que ele se ausenta ao menos oito horas diárias do convívio com a família. Além disso, é responsável pela compra de alimentos, fato que foi apontado por cinco mães de ambos os grupos e que, de certo modo, reforça o papel do homem como provedor financeiro (Teykal \& Rocha-Coutinho, 2007). 
Este trabalho foi realizado com uma composição mista de jornadas de trabalho maternas, ou seja, mães que trabalhavam entre 30 e 40 horas semanais. Esse fator pode ter contribuído para o resultado positivo desta pesquisa. Estudos (Bossardi, 2011; Giallo et al., 2013) apontam que, quanto menor a jornada de trabalho materna (ou quando é de meio período), maior é o engajamento da mãe com o bebê, ou seja, a quantidade de horas que a mãe trabalha influência no engajamento. A realização de outras pesquisas, com a participação de mulheres que trabalham em jornada de trabalho integral ou plantão, pode contribuir na medida em que verifiquem possíveis diferenças no tempo dedicado ao bebê em função das horas trabalhadas, considerando a especificidade desses tipos de jornada (Craig et al., 2014; Huston \& Aronson, 2005).

Conclui-se que os resultados não evidenciaram prejuízos para mães e bebês quando as mães, desta amostra, trabalhavam fora. Pelo contrário, verificou-se que, em alguns momentos, o tempo que elas dedicavam à maternidade e aos cuidados com o filho era igual ou maior do que o tempo dedicado pelas mães que não trabalhavam. A esse respeito, Ribeiro, Perosa e Padovani (2013) concluíram que bebês de cerca de um ano, que moravam em bairros periféricos e eram atendidas em Unidades de Saúde da Família, apresentaram maior desenvolvimento quando suas mães exerciam atividades remuneradas, e sugerem que essa temática seja mais explorada.

Os achados desta pesquisa contribuem para a literatura (Craig et al., 2014; Milkie et al., 2015; Wall, 2013) na medida em que auxiliam na desmistificação da ideia de que a mãe que não exerce atividade remunerada se dedica intensivamente à criança e, por isso, provê atividades mais estimuladoras e melhor desenvolvimento ao seu filho, enquanto a mãe que exerce atividade remunerada supostamente não tem o tempo necessário para ficar com seus bebês. Além disso, este estudo corrobora a literatura na medida em que indica quanto espaço ainda há disponível na vida doméstica e nos cuidados com o bebê para atuação masculina, de modo que essa atuação resulte em melhor divisão de tarefas entre o casal.

\section{Considerações finais}


Esta pesquisa teve como objetivo identificar diferenças no tempo de cuidado que mães que trabalham fora e mães que não trabalham fora dedicam ao bebê. Além disso, buscou-se conhecer a realidade dessas mães quanto à divisão de tarefas com o companheiro e a rede de apoio social. Destacou-se a baixa participação dos pais nos afazeres domésticos, embora, com relação aos cuidados do bebê, tenha-se verificado mudança no padrão tradicional, ainda que a mulher continue a ser a principal responsável. Além disso, destacou-se a participação das avós, tanto no auxílio aos cuidados com o bebê, quanto no auxílio aos afazeres domésticos, demonstrando que elas têm papel fundamental na dinâmica familiar.

Entre as dificuldades encontradas para a composição da amostra, destaca-se a indisponibilidade das mães, principalmente entre as que não trabalhavam fora de casa. Os dados aqui apresentados refletiram o resultado de um pequeno grupo, de nível socioeconômico privilegiado e em condições de optar ou não pelo trabalho externo. Sugerese que novos estudos sejam realizados, visando comparar mães que trabalham em tempo integral, parcial e mães que não trabalham fora, a fim de verificar possíveis diferenças no tempo de interação exclusivo entre a díade mãe-bebê. Além disso, seria importante incluir dados relacionados à saúde mental materna, com o intuito de averiguar a influência dessa variável nos resultados. Novos estudos com populações de menor nível socioeconômico são necessários para verificar se há diferença no tempo de dedicação ao bebê em outras parcelas da população, considerando que os níveis educacional e econômico podem influenciar nos resultados obtidos. Por fim, acredita-se que os dados desta pesquisa possam contribuir para a temática, na medida em que evidencia o trabalho como um dos fatores que podem colaborar para a qualidade da relação mãe-bebê e cuidado materno e, não, como determinante de diferenças negativas referentes a essas questões.

\section{Referências}

Amaral, G. A. (2012). Os desafios da inserção da mulher no mercado de trabalho. Itinerarius Reflectionis, 8(2), 1-20. https://doi.org/10.5216/rir.v2i13.22336 
Ávila, M. B., \& Ferreira, V. (2014). Trabalho produtivo e reprodutivo no cotidiano das mulheres brasileiras. In M. B. Ávila, \& V. Ferreira (Orgs.), Trabalho remunerado e trabalho doméstico no cotidiano das mulheres (pp. 13-46). Recife: SOS Corpo.

Borsa, J. C., \& Nunes, M. L. T. (2011). Prevalência de problemas de comportamento em uma amostra de crianças em idade escolar da cidade de Porto Alegre. Aletheia, (34), 32-46. http:/ / pepsic.bvsalud.org/pdf/ptp/v13n2/v13n2a02.pdf

Bossardi, C. N. (2011). Relação do engajamento parental e conflito conjugal no investimento com os filhos [Dissertação de Mestrado, Universidade Federal de Santa Catarina]. Repositório Institucional

$\mathrm{da}$

UFSC. http:/ / repositorio.ufsc.br/xmlui/handle/123456789/95383

Brasil, República Federativa do Brasil. Instituto Brasileiro de Geografia e Estatística. (2013). Síntese de indicadores sociais 2013. Uma análise das condições de vida da população $\begin{array}{llll}\text { brasileira. } & \text { Rio de Janeiro: }\end{array}$ https://ww2.ibge.gov.br/home/presidencia/noticias/imprensa/ppts/000000154717111 $02013171529343967 . p d f$

Brasil, República Federativa do Brasil. Instituto Brasileiro de Geografia e Estatística. (2014). Estatísticas de gênero. Uma análise dos dados resultados do censo demográfico 2010. Rio de Janeiro: IBGE. https://biblioteca.ibge.gov.br/visualizacao/livros/liv88941.pdf

Brasil, República Federativa do Brasil. Instituto Brasileiro de Geografia e Estatística. (2016). Pesquisa nacional por amostra de domicílios. Síntese de indicadores 2015. Rio de Janeiro: IBGE. https://biblioteca.ibge.gov.br/visualizacao/livros/liv98887.pdf

Brasil, República Federativa do Brasil. Instituto Brasileiro de Geografia e Estatística. (2018). Pesquisa Nacional por Amostra de Domicílios Contínua 2017: Outras formas de trabalho. Rio de Janeiro: IBGE. https://biblioteca.ibge.gov.br/visualizacao/livros/liv101560_informativo.pdf

Craig, L., Powell, A., \& Smyth, C. (2014). Towards intensive parenting? Changes in the composition and determinants of mothers' and fathers' time with children 1992-2006.

The British Journal of Sociology, 65(3), 555-579. https://doi.org/10.1111/14684446.12035 
Crowley, J. E. (2014). Staying at Home or Working for Pay? Attachment to Modern Mothering Identities. Sociological Spectrum, $34(2), \quad 114-135$. https:// doi.org/10.1080/02732173.2014.878605

Dessen, M. A. (2009). Questionário de caracterização do sistema familiar: Versão - pais ou responsável. In L. Weber, \& M. A. Dessen (Orgs.), Pesquisando a família: instrumentos para coleta e análise de dados (pp. 115-131). Curitiba: Juruá.

Dessen, M. A., \& Braz, M. P. (2000). Rede social de apoio durante transições familiares decorrentes do nascimento de filhos. Psicologia: Teoria e Crítica, 16(3), 221-231. https://doi.org/10.1590/S0102-37722000000300005

Dias Junior, C. S., \& Verona, A. P. (2016). Maternidade e trabalho: algumas reflexões sobre mulheres em ocupações de nível superior. Revista Brasileira De Sociologia, 4(7), 111 133. https://doi.org/10.20336/rbs. 152

Dush, C. M. H., Yavorsky, J. E., \& Schoppe-Sullivan, S. J. (2018). What Are Men Doing while Women Perform Extra Unpaid Labor? Leisure and Specialization at the Transitions to Parenthood. Sex Roles, 78, 715-730. https://doi.org/10.1007/s11199-017-0841-0

Faria, A., Santos, P. L., \& Fuertes, M. (2014). Pais e mães protegem, acarinham e brincam de formas diferentes. Análise Psicológica, 32(4), 419-437. https:// doi.org/1014417/ap.32.3.698

Giallo, R., Treyvaud, K., Cooklin, A., \& Wade, C. (2013). Mothers' and fathers' involvement in home activities with their children: psychosocial factors and the role of parental selfefficacy. Early Child Development and Care, 183(3-4), 343-359. https:// doi.org/10.1080/03004430.2012.711587

Guedes, M. C., \& Alves, J. E. D. (2004). A população feminina no mercado de trabalho entre 1970-2000: particularidades do grupo com nível universitário. Anais do XIV Encontro Nacional de Estudos Populacionais (pp. 1-19). Caxambú: ABEP. http:/ / www.abep.org.br/publicacoes/index.php/anais/article/viewFile/1307/1271

Huston, A. C., \& Aronson, S. R. (2005). Mothers' time with infant and time in employment as predictors of mother-child relationships and children's early development. Child Development, 76(2), 467-482. https://doi.org/10.1111/j.1467-8624.2005.00857.x 
Jablonski, B. (2010). A divisão de tarefas domésticas entre homens e mulheres no cotidiano do casamento. Psicologia Ciência e Profissão, 30(2), 262-275. https://doi.org/10.1590/S1414-98932010000200004

Jorge, E. R. M. (2011). Trabalho vs. Família: o envolvimento parental nas diferentes dimensões da dinâmica familiar [Dissertação de Mestrado, Instituto Superior de Psicologia Aplicada].

Kobarg, A. P. (2006). Crenças e práticas de mães sobre o desenvolvimento infantil nos contextos rural e urbano [Dissertação de Mestrado, Universidade Federal de Santa $\begin{array}{lllll}\text { Catarina]. } & \text { Repositório } & \text { Institucional }\end{array}$ http:/ / repositorio.ufsc.br/xmlui/handle/123456789/89118

Lopes, M. N., Dellazzana-Zanon, L. L., \& Boeckel, M. G. (2014). A multiplicidade de papéis da mulher contemporânea e a maternidade tardia. Temas em Psicologia, 22(4), 917-928. https:// doi.org/10.9788/TP2014.4-18

Manente, M. V., \& Rodrigues, O. M. P. (2016). Maternidade e trabalho: Associação entre depressão pós-parto, apoio social e satisfação conjugal. Pensando Famílias, 20(1), 99111. http:// pepsic.bvsalud.org/pdf/penf/v20n1/v20n1 a08.pdf

Mendonça, M., \& Matos, P. M. (2015). Conciliação família-trabalho vivida a dois: Um estudo qualitativo com casais com filhos pequenos. Análise Psicológica, 33(3), 317-334. https:// doi.org/10.14417/ap.904

Milkie, M. A., Nomaguchi, K. M., \& Denny, K. E. (2015). Does the amount of time mothers spend with children or adolescents matter? Journal of Marriage and Family, (77), 355372. https://doi.org/10.1111/jomf. 12170

Oliveira, C. R., \& Traesel, E. S. (2008). Mulher, trabalho e vida familiar: A conciliação de diferentes papéis na atualidade. Disciplinarum Scientia, 9(1), 149-163. https://www.periodicos.unifra.br/index.php/disciplinarumS/article/view/943/886

Peruchi, R. C., Donelli, T. M. S., \& Marin, A. H. (2016). Ajustamento conjugal, relação mãebebê e sintomas psicofuncionais no primeiro ano de vida. Quaderns de Psicologia, 18(3), 55-67. https://doi.org/10.5565/rev/qpsicologia.1363

Quadrelli, I. P. (2016). Vai ter coragem? Uma descrição fenomenológica da relação entre maternidade e trabalho [Dissertação de Mestrado, Universidade Católica de Brasília]. 
Biblioteca Digital de Dissertações da Universidade Católica de Brasília. https://bdtd.ucb.br:8443/jspui/handle/tede/2086

Ribeiro, D.G., Perosa, G. B., \& Padovani, F. H. P. (2013). Fatores de risco para o desenvolvimento de crianças atendidas em Unidades de Saúde da Família, ao final do primeiro ano de vida: aspectos sociodemográficos e de saúde mental materna. Ciência e Saúde Coletiva, 19(1), 215-226. https://doi.org/10.1590/1413-81232014191.1904

Rodrigues, B. C., Mazza, V. A., \& Harumi, I. H. (2014). Rede social de apoio de enfermeirasmães no cuidado com os filhos. Texto \& Contexto Enfermagem, 23(2), 460-468. https:// doi.org/10.1590/0104-0707014001070013

Santos, L. S. (2014). Donas de casa, donas da própria vida? Problematizações acerca do trabalho (in)visível e da saúde mental de mulheres (des)valorizadas [Tese de Doutorado, Universidade de Brasília]. Repositório Institucional da UnB. https:/ / repositorio.unb.br/handle/10482/18355

Silva, A. P. G. (2010). Percepções de avós cuidadoras maternas sobre a criação e educação dos netos [Dissertação de Mestrado, Universidade Federal de Juiz de Fora]. Repositório Institucional da UFJF. https://repositorio.ufjf.br/jspui/handle/ufjf/2515

Souza, B. M. S., Souza, S. F., \& Rodrigues, R. T. S. (2013). Puerpério e a mulher contemporânea: uma investigação sobre a vivência e os impactos da perda da

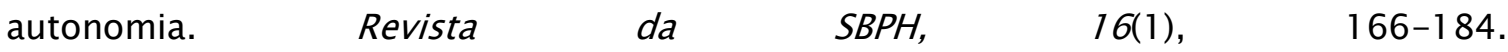
http://pepsic.bvsalud.org/scielo.php?script=sci_arttext\&pid=S151608582013000100010

Teykal, C. M., \& Rocha-Coutinho, M. L. (2007). O homem atual e a inserção da mulher no mercado de trabalho. PSICO, 38(3), 262-268. http://revistaseletronicas.pucrs.br/ojs/index.php/revistapsico/article/view/2888/

Theme Filha, M. M., Ayres, S., Gama, S. G. N., \& Leal, M. C. (2016). Factors associated with postpartum depressive symptomatology in Brazil: The birh in Brazil national research study, 2011/2012. Journal of Affective Disorders, 194, 159-167. https://doi.org/10.1016/jad.2016.01.020

Troiano, C. (2007). Vida de equilibrista: dores e delícias da mãe que trabalha. São Paulo: Cultrix. 
Wall, G. (2013). 'Putting Family first: Shifting discourses of motherhood and childhood in representations of mothers' employment and child care. Women's Studies International Forum, 40, 162-171. https://doi.org/10.1016/j.wsif.2013.07.006

Recebido em: 27/7/2018

Aprovado em: 22/3/2019 